\title{
Protective Effect of Quercetin on Azithromycin Induced Hepatotoxicity and Nephrotoxicityin Wistar Rats
}

\author{
S. V. Usadadia ${ }^{*}$ J. M. Patel, P. D. Vihol and A. P. Urkude \\ Department of Veterinary Pathology, College of Veterinary Science and Animal Husbandry, \\ Navsari Agricultural University, Navsari-396450, Gujarat, India \\ *Corresponding author
}

\section{A B S T R A C T}

\section{Keywords}

Azithromycin,

Biochemical,

Histopathological parameter,

Hepatotoxicity, Nephrotoxicity,

Quercetin

\section{Article Info}

Accepted:

20 August 2020

Available Online:

10 September 2020
The aim of this study was to investigate the possible protective role of flavonoid quercetin on azithromycin induced toxicity using biochemical and histopathological approaches. In experimental rats oral administration of azithromycin $(30 \mathrm{mg} / \mathrm{kg} \mathrm{b}$.wt. $)$ for 4 weeks significantly induced liver and renal damage which was evident from the significant $(\mathrm{P}<0.05)$ increased levels of liver enzymes (AST and ALT) activities, total bilirubin and creatinine concentration. Moreover, the liver of azithromycin treated rats showed severe sinusoidal hemorrhages, congestion, vacuolar degeneration, fatty changes and disruption of hepatic cords were seen. The lesions in kidneys consisted of severe tubular and cortical hemorrhages, luminal cast formation and desquamous of tubular lining epithelium. Increased space between cardiac muscle fibers, severe hemorrhages and infiltration of inflammatory cells were seen in heart. Quercetin treatment markedly attenuated the azithromycin induced biochemical alterations in serum. Quercetin also ameliorated the azithromycin induced pathological changes when compared with azithromycin alone treated group. These data indicate that the natural dietary antioxidant quercetin had protective effect against azithromycin induced hepatotoxicity and nephrotoxicity in rats.

\section{Introduction}

Azithromycin is antibiotics with bactericidal and bacteriostatic activities and is frequently prescribed for the treatment of upper and lower respiratory tract, pharyngitis, tonsillitis, dermatological infections, streptococcal pharyngitis, urogenital infections, otitis media and sexually transmitted disease due to chlamydia and gonorrhea (Cunha, 1996, Duran et al., 2000 and Holmes, 2005). Azithromycin is the best seller antibiotic in the USA, ranked $15^{\text {th }}$ among the mostlyprescribed medications. Even though rare incidence of cardiotoxicity (Giudicessi and Ackerman, 2013) and cardiac arrhythmias were reported when given by rapid intravenous administration or in overdose (Tilelli et al., 2006). The effects of azithromycin on liver damage have been well documented in clinical studies (Er, 2010, Lockwood et al., 2010). Interstitial nephritis (Mansoor et al., 1993, Soni et al., 2004) and chronic renal failure after the second 
occurrence of acute interstitial nephritis have been reported in clinical studies of azithromycin (Persico et al., 2011). Flavonoids are a group of natural antioxidants which are non-nutritive dietary components that are widely distributed in plants. Flavonoids affect basic cell function such as growth, differentiation and apoptosis, because of their radical scavenging activity and proposed to exert beneficial effects in cancer, cardiovascular disease and neurodegenerative disorders.

Quercetin is one of the most frequently studied bioflavonoid in the class of flavonols. Quercetin is natural flavonoid present in high concentration in herbal drugs, fruits and vegetables like apples, onion, potatoes, broccoli, tea, soybeans, red wine. It is demonstrating broad biopharmacological properties (Renugadevi and Prabu, 2010).

Quercetin is a more potent antioxidant than other antioxidant nutrients such as vitamin $\mathrm{C}$, vitamin $\mathrm{E}$ and $\beta$-carotene on a molar basis (Rice-Evans et al.,1995) and it causes cytoprotective effects which prevents endothelial apoptosis caused by oxidants, directly scavenging free radical and induces hepatoprotectivity effects (Choi et al., 2003, Renugadevi and Prabu, 2010). It can chelate transition metal ions, including iron, thus preventing iron catalyzed fenton reaction (Ferrali et al., 2000).

Epidemiological studies have suggested that the intake of food containing flavonoids may be associated with reduced risk of coronary heart disease, hyper cholesterolemia, atherosclerosis and heart failure (Hollman and Katan, 1999, Stoclet et al., 2004). It is marketed as a diet supplement with antihistamine, anti-inflammatory, antiviral, immunomodulatory and antioxidant properties (Ross and Kasum, 2002). It also possesses anti tumoral, antifungal, vasorelaxation activity on hippocampal neurons ( $\mathrm{Pu}$ et al., 2007). It scavenges superoxide in ischemia reperfusion injury (Huk et al., 1998).

\section{Materials and Methods}

\section{Drugs and Chemicals}

Azithromycin dihydrate $\geq 98 \%$ (HPLC) (Sigma-Aldrich) and quercetin were used in experiment. Carboxy Methyl Cellulose (CMC) was used as a vehicle to formulate the dose.

\section{Animals}

A total 40 Wistar rats of either sex weighing 250-350 g were procured from Jay Research Foundation, Vapi, Gujarat. The study was carried out after ethical approval by Institutional Animal Ethical Committee (IAEC) (No.064-VCN-VPP-2018). Rats were maintained in an environmentally controlled room at a temperature of $22 \pm 3^{\circ} \mathrm{C}$ and relative humidity of 40 to 70 percent with natural light-dark cycle. The rats were acclimatized to laboratory conditions for ten days. The animals were housed, five number of same sex rats in polypropylene cage with solid bottom having autoclaved paddy husk as bedding materials. The experimental rats were fed on standard rodent pellet feed with ad libitum clean and filtered drinking water in polypropylene bottles.

\section{Animal Experiment}

The animals were randomly divided into four different groups with 5 male and 5 female rats in each group. The rats in group-I were orally administered $0.5 \mathrm{ml}$ of Carboxy Methyl Cellulose (CMC) and served as control. The rats in group-II were administered azithromycin alone (30 mg/kg b.wt.) for the period of 4 weeks. The rats in group-III were 
administered quercetin alone (50 mg/kg b.wt.) for the period of 4 weeks. The rats in groupIV administered azithromycin (30 mg/kg b.wt) and quercetin (50 mg/kg b.wt.) for the period of 4 weeks.

Rats were observed daily for abnormal clinical signs. For blood collection, rats were anaesthetized using chloroform. Blood sample were collected from retro orbital venous plexus using rat capillaries at $0,15^{\text {th }}, 28^{\text {th }}$ day of experiment in plain vial for separation of serum sample(blood coagulate at room temperature followed by centrifugation at $1000 \mathrm{rpm}$ for ten minutes at $4^{\circ} \mathrm{C}$ for serum separation) for serum biochemical estimations.

At the end of experiment, the rats were sacrificed by over dose of ether inhalation. A detailed necropsy examination of each rat of different groups was performed and liver, kidneys and heart dissected out and fixed in $10 \%$ neutral buffered formalin for histopathological examination.

\section{Methods}

\section{Estimation of biochemical parameters}

The levels of ALT, AST, Creatinine, Blood urea nitrogen (BUN), Total bilirubin and blood glucose were estimatedwith the help of semi-automatic biochemical analyzer (Micro lab Instrument, Model: ARX-3) using diagnostic kits as per kit literature (Brand: Randox, Manufacturer: Randox Laboratories Ltd).

\section{Histopathological examination}

The liver, kidneys and heart excised after necropsy. The tissues were fixed in $10 \%$ neutral buffered formalin, embedded in paraffin, sectioned at $5 \mu \mathrm{m}$ and were stained with hematoxylin and eosin. Hepatic tissues showed severe sinusoidal hemorrhages, congestion, vacuolar degeneration, fatty changes and desruption of hepatic cords.

Tubular injury was defined as severe tubular and cortical hemorrhages, luminal cast formation and desquamous of tubular lining epithelium. Increase space between cardiac muscle fibers, severe hemorrhages and infiltration of inflammatory cells were seen in heart.

\section{Statistical Analysis}

All the data were expressed as mean $( \pm \mathrm{SE})$ of a number of experiments $(n=10)$. The statistical significance was evaluated by using SPSS 16.0 statistical software (SPSS, Inc., 2007). One-way analysis of variance (ANOVA) followed by Duncan's test was performed to determine intergroup differences. The criterion for statistical significance was $\mathrm{P}<0.05$.

\section{Results and Discussion}

The alteration value of ALT, AST, total bilirubin and creatinine in serum in control and experimental rats are shown in Table 1. A significant $(p<0.05)$ increase in level of ALT, AST, total bilirubin and creatinine was observed in serum of only azithromycin treated rats when compared with normal rats.

Administration of quercetin $(50 \mathrm{mg} / \mathrm{kg}$ per day) along with azithromycin significantly $(\mathrm{p}<0.05)$ restored the levels of ALT, AST, total bilirubin and creatinine to near normal levels when compared with azithromycin alone treated rats (Fig.1 A, B, C and D).

Histopathological changes in the liver and kidney were evaluated as described in materials and methods and the results are presented in histopathological slides. 
Table.1 Biochemical enzyme activities values in different treatment groups at different time intervals

\begin{tabular}{|c|c|c|c|c|}
\hline Parameters Studied & Groups $n=10$ & 0 Day & 15 Day & 28 Day \\
\hline \multirow{4}{*}{$\begin{array}{c}\mathbf{A S T} \\
(\mathbf{U} / \mathbf{L})\end{array}$} & Gr.1 & $77.72 \pm 2.66$ & $81.35^{c} \pm 2.66$ & $83.60^{c} \pm 2.67$ \\
\hline & Gr.2 & $78.28 \pm 2.79$ & $157.19^{a} \pm 7.07$ & $194.18^{a} \pm 6.86$ \\
\hline & Gr.3 & $82.22 \pm 2.86$ & $94.37^{c} \pm 2.67$ & $95.08^{c} \pm 4.41$ \\
\hline & Gr.4 & $83.08 \pm 2.05$ & $136.37^{\mathrm{b}} \pm 5.08$ & $148.73^{b} \pm 4.21$ \\
\hline \multirow{4}{*}{$\begin{array}{l}\mathbf{A L T} \\
(\mathbf{U} / \mathbf{L})\end{array}$} & Gr.1 & $43.12 \pm 1.40$ & $49.27 \pm 2.58$ & $51.93^{b} \pm 1.78$ \\
\hline & Gr.2 & $46.61 \pm 1.39$ & $48.99 \pm 1.50$ & $60.60^{a} \pm 3.54$ \\
\hline & Gr.3 & $41.95 \pm 2.65$ & $48.55 \pm 3.07$ & $52.05^{b} \pm 1.89$ \\
\hline & Gr.4 & $41.10 \pm 1.54$ & $55.66 \pm 4.84$ & $54.35^{\mathrm{ab}} \pm 2.00$ \\
\hline \multirow{4}{*}{$\begin{array}{l}\text { Total bilirubin } \\
\text { (mg/dl) }\end{array}$} & Gr.1 & $0.70 \pm 0.05$ & $0.71^{b} \pm 0.07$ & $0.70^{b} \pm 0.09$ \\
\hline & Gr.2 & $0.63 \pm 0.07$ & $1.10^{\mathrm{a}} \pm 0.15$ & ${ }^{a} \pm 0.11$ \\
\hline & Gr.3 & $0.56 \pm 0.08$ & $0.64^{b} \pm 0.04$ & $0.62^{b} \pm 0.12$ \\
\hline & Gr.4 & $0.65 \pm 0.05$ & $0.90^{\mathrm{ab}} \pm 0.10$ & $0.77^{\mathrm{ab}} \pm 0.07$ \\
\hline \multirow[t]{4}{*}{ Creatinine (mg/dl) } & Gr.1 & $0.63 \pm 0.07$ & $0.63 \pm 0.07$ & $0.63^{b} \pm 0.07$ \\
\hline & Gr.2 & $0.46 \pm 0.10$ & $0.82 \pm 0.09$ & $0.95^{\mathrm{a}} \pm 0.07$ \\
\hline & Gr.3 & $0.63 \pm 0.06$ & $0.77 \pm 0.05$ & $0.72^{b} \pm 0.02$ \\
\hline & Gr.4 & $0.58 \pm 0.08$ & $0.59 \pm 0.08$ & $0.68^{b} \pm 0.07$ \\
\hline
\end{tabular}

Note: Treatments bearing different superscripts in a column differ significantly at $\mathrm{P}<0.05$ (DMRT).

$* 0$ day $=$ at initiation of dosing

Fig.1 Effect of quercetin on azithromycin induced changes in liver and kidneys enzymes: (A) AST,(B) ALT, (C) Serum creatinine and (D) Total bilirubin in Wistar rats. Values are mean \pm SE for ten rats in each group. ${ }^{\mathrm{a}, \mathrm{b}, \mathrm{c}}$ Bars not sharing a common superscript letter $(\mathrm{a}, \mathrm{b}, \mathrm{c})$ differ significantly at $\mathrm{P}<0.05$ (DMRT)
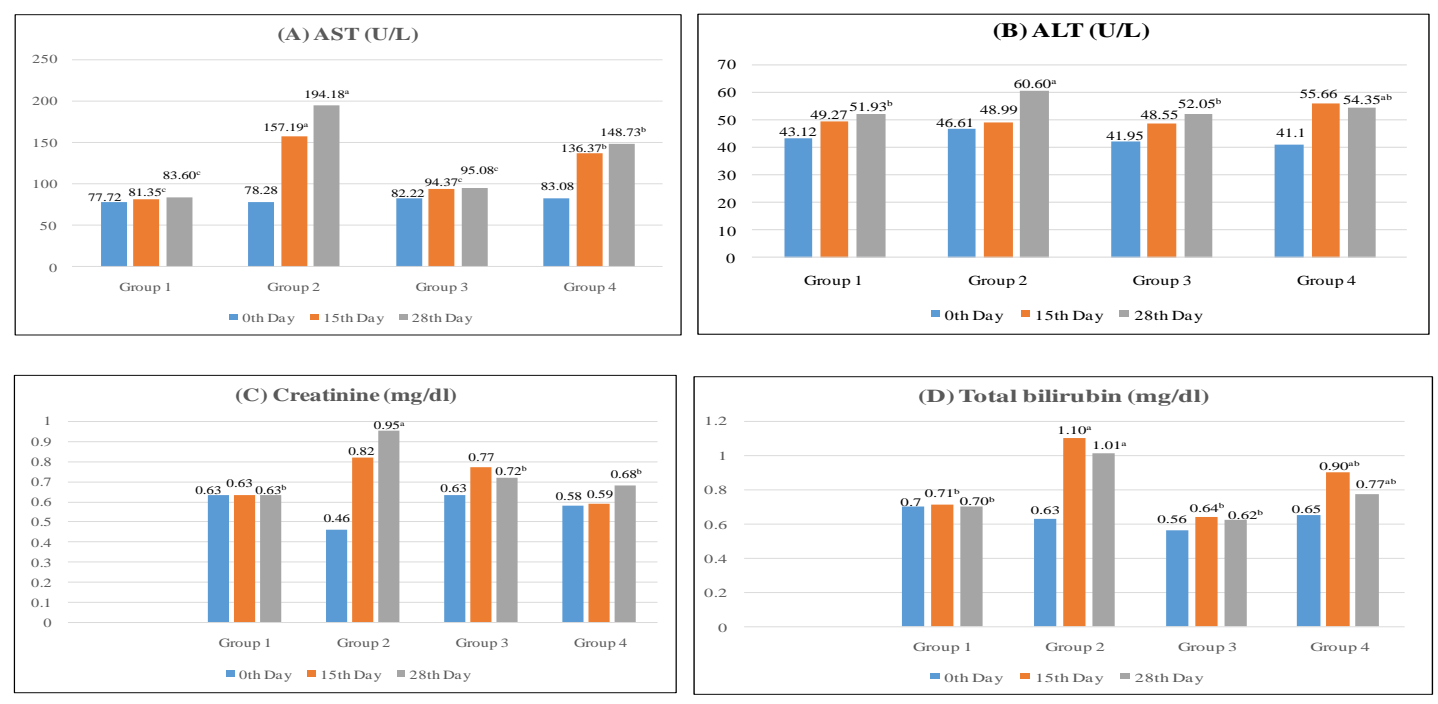
Fig.2 (A) Severe sinusoidal hemorrhages in liver, (B) Liver showing disruption of hepatic cord, (C) Mild infiltration of inflammatory cells in liver, (D) Liver showing vacuolated cytoplasm in hepatocytes, (E) Fatty changes in hepatocytes, (F) Luminal cast formation in kidney, (G) Severe hemorrhages in kidney, $(\mathrm{H})$ Mild degenerative changes in liver after treatment with quercetin, (I)

Mild hemorrhages and degenerative changes in kidney after treatment with quercetin
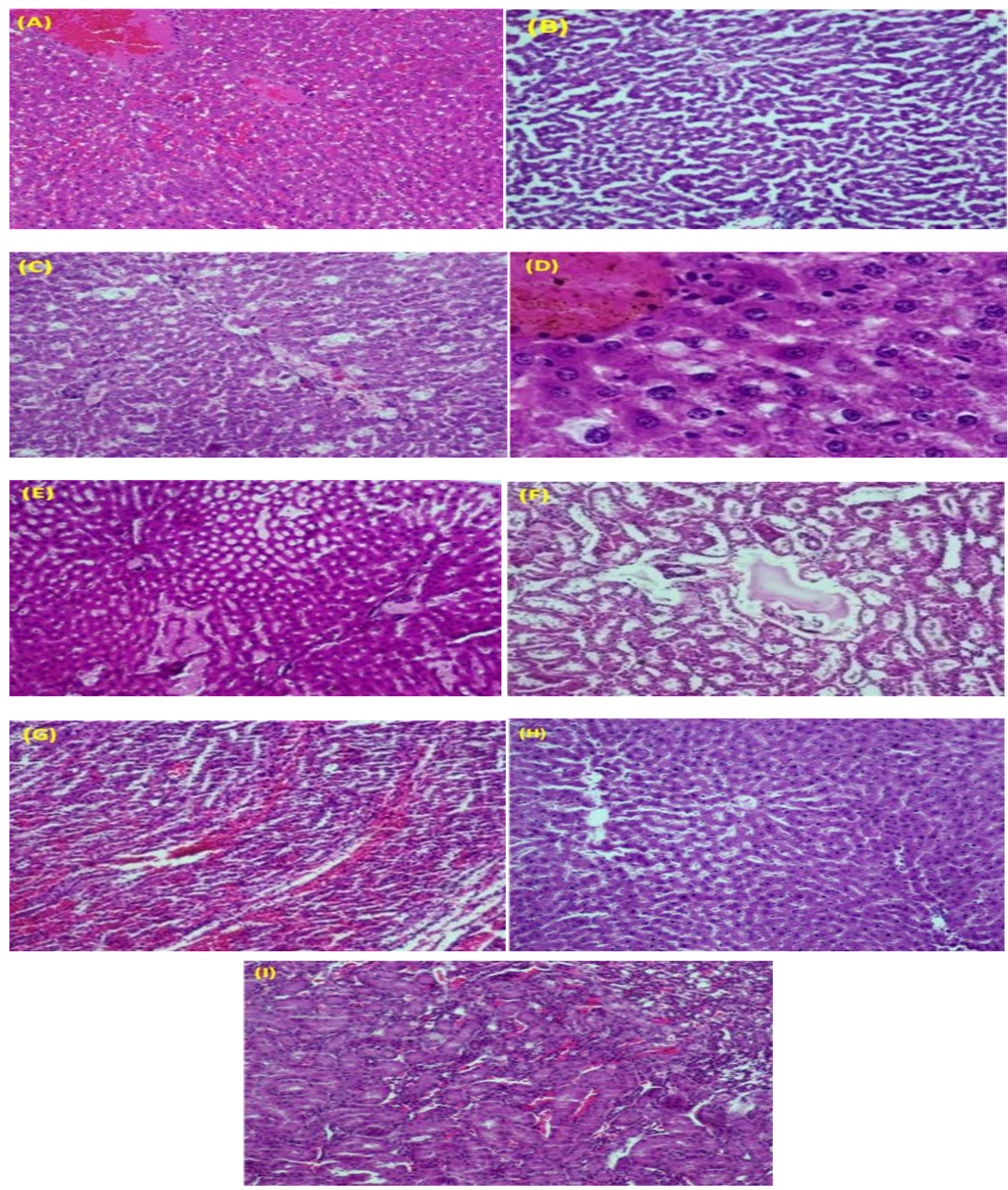

Treatment with azithromycin caused severe sinusoidal hemorrhages and congestion, disruption of hepatic cords, inflammatory cells infiltration, vacuolar degeneration and fatty changes. (Fig.2 A,B,C,D,E). In kidney azithromycin cause luminal cast formation severe tubular and cortical hemorrhages and desquamous of tubular lining epithelium (Fig.2 F,G). However treatment with quercetin ameliorated the hepatic and tubular (Fig.2 H,I). There were no histopathological changes observed in rats treated with quercetin alone and in the control rats.

Azithromycin is frequently prescribed for the treatment of many infectious conditions. Azithromycin are lipophilic and are extensively distributed in body fluids and tissues and it exerts its antibacterial action, even though it affects liver, kidneys and heart. Hoe and Wilkinson (1973) reported that in the event of any cell wall damage, the 
permeability of cell membrane either increased or the cell wall ruptured resulting in diffusion of the enzyme into the blood stream causing increased serum enzyme activity. The hepatotoxic effects of azithromycin appeared due to the generation of highly reactive free radicals because of oxidative threat caused by the drug which disrupted normal cellular functioning of the liver and kidney (Olayinka and Ore, 2014). In the present study increased activities of liver enzymes (AST and ALT) and total serum bilirubin concentration in serum of rats which attributed to the liver dysfunction. These results are in consistence with previous reports for drug induced liver toxicity (Cascaval and Lancaster, 2001; Chandrupatla et al., 2002; Suriawinata and Min, 2002; Baciewicz et al., 2005; Charest et al., 2010; Das, 2011; Maggioli et al., 2011; Olayinka and Ore, 2014; Martinez et al.,2015 and Mobasher Ahmad et al., 2018). However, Paulose et al., (2016) reported liver ALT values were significantly decreased in azithromycin treated group, indicating the hepatotoxic potential of the antibiotic at $30 \mathrm{mg} / \mathrm{kg}$ body weight because once the cell death happened, the source of enzyme declined.

Quercetin decreased the lipid peroxidation in the cell membranes (Gupta et al., 2010) resulting suppresses the leakage of AST and ALT enzymes into blood circulation. In the present study reduced activities of liver enzymes (AST and ALT) by quercetin were reported. Similar to the present findings, Janbaz et al., (2004); Chen (2010); Gupta et al., (2010); Yousef et al., (2010); De David et al., (2011); Selvakumar et al., (2012); Uzun and Kalender (2013); El Nekeety et al., (2014) and Afifi et al., (2018) also observed comparatively protective effect of quercetin. The hepatoprotective effect might be a result of the stabilization in the redox state and maintenance of the antioxidant capacity offered by quercetin. It could be also attributed to calcium channel blocking activity exerted by quercetin (Kurose, 1981). Calcium contents in liver cells are liable to be increased during the process of experimental liver damage and calcium channel blocking drugs were found to inhibit the development of hepatic damage induced by different hepatotoxins (Thibault et al., 1991). The hepatoprotective effect may be mediated through combination of multiple mechanisms, such as reported anti-oxidant, free radical scavenging, anti-inflammatory, calcium channel blocking and microsomal enzyme inhibitory action (Janbaz et al., 2004).

Creatinine and urea are metabolic waste products that are freely filtered by the glomeruli of the kidneys (Gaspari et al., 1998) and their serum/plasma concentrations are commonly used to screen for renal diseases (Ogawa, 1992 and Traynor et al., 2006). Elevation of the plasma levels of creatinine and urea is an indication of abnormal renal function (Mouton and Holder, 2006). In present study serum concentration increased significantly in the azithromycin treated group of rats suggesting impairment of renal function. Whereas, BUN concentration did not show any significant variation. Increased serum creatinine concentration and BUN level observed by Soni et al., (2004); Persico et al., (2011); Olayinka and Ore (2014) and Mobasher Ahmad et al., (2018). In this experiment quercetin significantly recovered the creatinine concentration in the serum of rats indicating its protective effect. Similar findings were also observed in previous studies (Renugadevi and Prabu, 2010; Yousef et al., 2010 and Ilic et al., 2014). The renal protection exerted by quercetin seems to be based on its abilityto increase metallothionein in kidneys (Morales et al., 2006). Metallothionein is a small cyteinerich protein that is induced by various stressors and it acts as a scavenger of heavy metals and as antioxidant. It is an efficient scavenger of 
hydroxyl radicals and can functionally substitute for SOD in oxidative stress (Vicente-Sanchez et al.,2008).

In conclusion, biochemical examination showed elevated liver and kidney enzymes and histopathological examination showed degenerative/necrotic changes, severe hemorrhages and vacuolar degeneration in liver; hemorrhages and degenerative changes in kidneys. These biochemical and histopathological changes improved by protective effect of quercetin at the dose rate of $50 \mathrm{mg} / \mathrm{kg} \mathrm{b.wt}$. in rats.

\section{Acknowledgement}

This work was carried out at Deparment of Veterinary Pathology, Navsari Agricultural University. We also acknowledge Jay Research Foundation, Vapi, Gujarat.

\section{References}

Afifi, N. A., Ibrahim, M. A. and Galal, M. K. (2018). Hepatoprotective influence of quercetin and ellagic acid on thioacetamide induced hepatotoxicity in rats. Canadian Journal of Physiology and Pharmacology, 96(6): 624-629.

Baciewicz, A. M., Al-Nimr, A. and Whelan, P. (2005). Azithromycin induced hepatoxicity. The American Journal of Medicine, 118(12): 1438-1439.

Cascaval, R.I. and Lancaster, D. J. (2001). Hypersensitivity syndrome associated with azithromycin. The American Journal of Medicine, 110(4): 330-331.

Chandrupatla, S., Demetris, A. J. and Rabinovitz, M. (2002). Azithromycin induced intrahepatic cholestasis. Digestive Diseases and Sciences, 47(10): 2186-2188.

Charest, D. M., Krogsgard, E. S. and Thomason, A. R. (2010). A Patient Case: Intravenous azithromycin induced hepatotoxicity. Hospital Pharmacy, 45(7): 545-548.

Chen, X. (2010). Protective effects of quercetin on liver injury induced by ethanol. Pharmacognosy magazine, 6(22): 135-141.
Choi, Y. J., Kang, J. S., Park, J. H. Y., Lee, Y. J., Choi, J. S. and Kang, Y. H. (2003). Polyphenolic flavonoids differ in their antiapoptotic efficacy in hydrogen peroxide treated human vascular endothelial cells. The Journal of Nutrition, 133(4): 985-991.

Cunha, B. A. (1996). Newer macrolide antibiotics: Advantages and uses. Advances in Therapy, 13(1): 29-37.

Das, B. K. (2011). Azithromycin induced hepatocellular toxicity and hepatic encephalopathy in asymptomatic dilated cardiomyopathy. Indian Journal of Pharmacology, 43(6): 736-737.

De David, C., Rodrigues, G., Bona, S., Meurer, L., Gonzalez Gallego, J., Tunon, M. J. and Marroni, N. P. (2011). Role of quercetin in preventing thioacetamide induced liver injury in rats. Toxicologic Pathology, 39(6): 949-957.

Duran, J. M. and Amsden, G. W. (2000). Azithromycin: indications for the future. Expert Opinion on Pharmacotherapy, 1(3): 489-505.

ElNekeety, A. A., Abdel Azeim, S. H., Hassan, A. M., Hassan, N. S., Aly, S. E. and Abdel Wahhab, M. A. (2014). Quercetin inhibits the cytotoxicity and oxidative stress in liver of rats fed aflatoxin contaminated diet. Toxicology reports, 1: 319-329.

Er, A. (2010). Effects of macrolide antibiotics on blood inflammatory mediators and organ damage markers in lipopolysaccharide induced pulmonary damage rats. Eurasian Journal of Veterinary Sciences, 26(1): 7-13.

Ferrali, M., Signorini, C., Ciccoli, L., Bambagioni, S., Rossi, V., Pompella, A. and Comporti, M. (2000). Protection of erythrocytes against oxidative damage and autologous immunoglobulin $\mathrm{G}$ ( $\mathrm{IgG})$ binding by iron chelator fluorbenzoil pyridoxal hydrazone. Biochemical Pharmacology, 59(11): 1365-1373.

Gaspari, F., Perico, N., Matalone, M., Signorini, O., Azzollini, N., Mister, M. and Remuzzi, G. (1998). Precision of plasma clearance of isohexol for estimation of GFR in patients with renal disease. Journal of the American Society of Nephrology, 9(2): 310-313.

Giudicessi, J. R. and Ackerman, M. J. (2013). Azithromycin and risk of sudden cardiac 
death: guilty as charged or falsely accused. Clevel and Clinic Journal of Medicine, 80(9): 539.

Gupta, C., Vikram, A.,Tripathi, D. N., Ramarao, P. and Jena, G. B. (2010). Antioxidant and antimutagenic effect of quercetin against DEN induced hepatotoxicity in rat. Phytotherapy Research, 24(1): 119-128.

Hoe, C. M. and Wilkinson, J. S. (1973). Liver function: a review. Australian Veterinary Journal, 49(3): 163-169.

Hollman, P. H. and Katan, M. B. (1999). Dietary flavonoids: intake, health effects and bioavailability. Food and Chemical Toxicology, 37(9-10): 937-942.

Holmes, K. K. (2005). Azithromycin versus penicillin $\mathrm{G}$ benzathine for early syphilis. The New England journal of Medicine, 353:1291-1293.

Huk, I., Brovkovych, V., Nanobashvili, J., Weigel, G., Neumayer, C., Partyka, L. and Malinski, T. (1998). Bioflavonoid quercetin scavenges superoxide and increases nitric oxide concentration in ischaemia reperfusion injury: an experimental study. British Journal of Surgery, 85(8): 1080-1085.

Ilic, S., Stojiljkovic, N., Veljkovic, M., Veljkovic, S. and Stojanovic, G. (2014). Protective effect of quercetin on cisplatin induced nephrotoxicity in rats. Facta Universitatis, Series: Medicine and Biology, 16(2): 71-75.

Janbaz, K. H., Saeed, S. A. and Gilani, A. H. (2004). Studies on the protective effects of caffeic acid and quercetin on chemical induced hepatotoxicity in rodents. Phytomedicine, 11(5): 424-430.

Kurose, M. (1981). Inhibition of anaphylactic histamine release from heterologously sensitized mast cells: differential effects of drugs which interfere with calcium influx. Acta Medica Okayama, 35(5): 307-317.

Lockwood, A. M., Cole, S. and Rabinovich, M. (2010). Azithromycin induced liver injury. American Journal of Health-System Pharmacy, 67(10): 810-814.

Maggioli, C., Santi, L., Zaccherini, G., Bevilacqua, V., Giunchi, F. and Caraceni, P. (2011). A case of prolonged cholestatic hepatitis induced by azithromycin in a young woman. Case Reports in Hepatology.

Mansoor, G. A., Panner, B. J. and Ornt, D. B.
(1993). Azithromycin-induced acute interstitial nephritis. Annals of Internal Medicine, 119(7): 636.

Martinez, M. A., Vuppalanchi, R., Fontana, R. J., Stolz, A., Kleiner, D. E., Hayashi, P. H. and Chalasani, N. (2015). Clinical and histologic features of azithromycin induced liver injury. Clinical Gastroenterology and Hepatology, 13(2): 369-376.

Mobasher Ahmad, I. M., Ikram, H., Anwar, R., Mobasher, A., Kamran, S. H. and Akhtar, U. (2018). Pharmacological investigation of Phoenix dactylifera L. in azithromycin induced Toxicity. Pharmacology, 14 (1): 6167.

Morales, A. I., Vicente-Sanchez, C., Sandoval, J. S., Egido, J., Mayoral, P., Arévalo, M. A. and Perez-Barriocanal, F. (2006). Protective effect of quercetin on experimental chronic cadmium nephrotoxicity in rats is based on its antioxidant properties. Food and ChemicalToxicology, 44(12): 2092-2100.

Mouton, R. and Holder, K. (2006). Laboratory tests of renal function. Anaesthesia and Intensive Care Medicine, 7(7): 240-243.

Ogawa, M. (1992). Present status and clinical therapy of pancreatic diseases. The Journal of the Japanese Society of Internal Medicine, 81(12): 1899-1900.

Olayinka, E. T. and Ore, A. (2014). Influence of azithromycin treatment on hepatic lipid peroxidation and antioxidant defence systems of rats.British Journal of Pharmaceutical Research, 4(2):240-256.

Paulose, P., Juliet, S., Samraj, S., Nair, S. N., Chandrasekhar, L., George, A. J. and Ravindran, R. (2016). Ameliorative effect of vitamin $\mathrm{E}$ on azithromycin induced biochemical and histological changes in liver tissue of rats. Advances in Animal and Veterinary Sciences, 4(2), 85-91.

Persico, C., Rocchi, A., Edefonti, A., Milani, G. P., Mazzoni, M. B. and Fossali, E. F. (2011). The acute interstitial nephritis induced by azithromycin. NDT plus, 4(3): 218.

$\mathrm{Pu}, \mathrm{F}$., Mishima, K., Irie, K., Motohashi, K., Tanaka, Y., Orito, K. and Fujiwara, M. (2007). Neuroprotective effects of quercetin and rutin on spatial memory impairment in an 8-arm radial maze task and neuronal death induced by repeated cerebral ischemia 
in rats. Journal of Pharmacological Sciences, 104(4): 329-334.

Renugadevi, J. and Prabu, S. M. (2010). Quercetin protects against oxidative stress related renal dysfunction by cadmium in rats. Experimental and Toxicologic Pathology, 62(5): 471-481.

Rice Evans, C. A., Miller, N. J., Bolwell, P. G., Bramley, P. M. and Pridham, J. B. (1995). The relative antioxidant activities of plant derived polyphenolic flavonoids. Free Radical Research, 22(4): 375-383.

Ross, J. A. and Kasum, C. M. (2002). Dietary flavonoids: bioavailability, metabolic effects and safety. Annual Review of Nutrition, 22(1): 19-34.

Selvakumar, K., Bavithra, S., Suganthi, M., Benson, C. S., Elumalai, P., Arunkumar, R. and Arunakaran, J. (2012). Protective role of quercetin on PCBs induced oxidative stress and apoptosis in hippocampus of adult rats. Neurochemical Research, 37(4): 708-721.

Soni, N., Harrington, J. W., Weiss, R., Chander, P. and Vyas, S. (2004). Recurrent acute interstitial nephritis induced by azithromycin. The Pediatric Infectious Disease Journal, 23(10): 965-966.

Stoclet, J. C., Chataigneau, T., Ndiaye, M., Oak, M. H., El Bedoui, J., Chataigneau, M. and SchiniKerth, V. B. (2004). Vascular protection by dietary polyphenols. European Journal of Pharmacology, 500(1-3): 299313.
Suriawinata, A. and Min, A. D. (2002). A 33year-old woman with jaundice after azithromycin use. In Seminars in liver disease, 22(2): 207-210.

Thibault, N., Peytavin, G. and Claude, J. R. (1991). Calcium channel blocking agents protect against acetaminophen- induced cytotoxicity in rat hepatocytes. Journal of Biochemical Toxicology, 6(3): 237-238.

Tilelli, J. A., Smith, K. M. and Pettignano, R. (2006). Life threatening bradyarrhythmia after massive azithromycin overdose. The Journal of Human Pharmacology and Drug Therapy, 26(1): 147-150.

Uzun, F. G. and Kalender, Y. (2013). Chlorpyrifos induced hepatotoxic and hematologic changes in rats: the role of quercetin and catechin. Food and Chemical Toxicology, 55: 549-556.

Vicente-Sanchez, C., Egido, J., SanchezGonzalez, P. D., Perez-Barriocanal, F., Lopez-Novoa, J. M. and Morales, A. I. (2008). Effect of the flavonoid quercetin on cadmium-induced hepatotoxicity. Food and Chemical Toxicology, 46(6): 2279-2287.

Yousef, M. I., Omar, S. A., El Guendi, M. I. and Abdelmegid, L. A. (2010). Potential protective effects of quercetin and curcumin on paracetamol induced histological changes, oxidative stress, impaired liver and kidney functions and haematotoxicity in rat. Food and Chemical Toxicology, 48(11): 3246-3261.

\section{How to cite this article:}

Usadadia, S. V., J. M. Patel, P. D. Vihol and Urkude, A. P. 2020. Protective Effect of Quercetin on Azithromycin Induced Hepatotoxicity and Nephrotoxicityin Wistar Rats. Int.J.Curr.Microbiol.App.Sci. 9(09): 2926-2934. doi: https://doi.org/10.20546/ijcmas.2020.909.360 